\title{
НАНЕСЕНИЕ МНОГОСЛОЙНЫХ ФУНКЦИОНАЛЬНЫХ ТОНКИХ ПЛЕНОК МЕТОДОМ МАГНЕТРОННОГО РАСПЫЛЕНИЯ НА УСТАНОВКЕ "МАГНА ТМ 150-01K"
} DEPOSITION OF MULTILAYER FUNCTIONAL THIN FILMS
BY THE METHOD OF MAGNETRON SPRAYING ON THE
"MAGNA TM 150-07K" INSTALLATION

\begin{abstract}
В.В.Одиноков, д.т.н., проф., заместитель генерального директора по науке, (ORCID: 0000-0003-1652-8013), P.А.Каракулов, инженер-технолог 1 категории, (ORCID: 0000-0003-1157-9225), В.В.Панин, к.т.н., начальник отдела исследований и испытаний, (ORCID: 0000-0002-1337-1375), А.В.Шубников, начальник отдела конструкторских разработок, (ORCID: 0000-0002-1137-808) / vodinokov@niitm.ru V.V.Odinokov, Doct. of Sc. (Engineering), Prof., Deputy Director General, (ORCID: 0000-0003-1652-8013), R.A.Karaulov, Engineer-technologist of $7^{\text {st }}$ grade, (ORCID: 0000-0003-7157-9225), V.V.Panin, Cand. of Sc. (Engineering), Head of Department, (ORCID: 0000-0002-1337-1375), A.V.Shubnikov, Head of Department, (ORCID: 0000-0002-1137-808)
\end{abstract}

DOI: 10.22184/1993-8578.2019.12.2.96.100

Получено: 18.03.2019г.

Представлена новая разработка ОАО "НИИ точного машиностроения" - вакуумная установка "МАГНА ТМ 150-01К". Рассмотрено ее устройство и принцип работы. На установке реализован технологический процесс нанесения многослойных тонких пленок на кремниевые пластины диаметром 100-150 мм магнетронным распылением. Покрытия наносились в едином вакуумном цикле с трех мишеней с загрузкой и выгрузкой пластин из кассеты в кассету в шлюзовой камере, встроенной в чистое помещение. Слои титана (Ti) и нитрида титана (TiN) наносились последовательно из одной титановой мишени, слой алюминия (Al) наносился из двух других алюминиевых мишеней.

This paper presents a new development of JSC "Research Institute of Precision Engineering" - vacuum installation "MAGNA TM 150-01K." Considered are the device and principle of operation. The installation implemented a technological process of deposition of multilayer thin films on the silicon wafers with a diameter of 100-150 mm by magnetron spaying. Coatings were applied in a single vacuum cycle from three targets with loading and unloading of plates from a cassette into a cassette in a lock chamber built into a clean room. Layers of titanium (Ti) and titanium nitride (TiN) were deposited sequentially from a single titanium target, and a layer of aluminum (Al) was deposited from two other aluminum targets.

П ри создании различных полупроводниковых устройств на основе тонкопленочных технологий для получения качественных многослойных покрытий необходимо наносить все слои на подложки в едином вакуумном цикле. Такая технология обеспечивает не только повышение производительности, но и увеличение прочности сцепления между основой и адгезионным слоем, а также между отдельными слоями покрытия [1].
Вместе с тем, актуальной задачей является создание отечественного специального технологического оборудования с возможностью загрузки/ выгрузки пластин из кассеты/в кассету и встраивания в чистые помещения. Оборудование дан ${ }^{-}$ ного типа должно удовлетворять основным требованиям по качеству получаемых тонкопленочных покрытий и иметь возможность работать в автоматическом режиме с контролем всех параметров

ОАО "НИИ точного машиностроения", 124460, Москва, Зеленоград, Россия / JSC "Research Institute of Precision Machine Manufacturing", Moscow, Zelenograd, Russian Federation. 


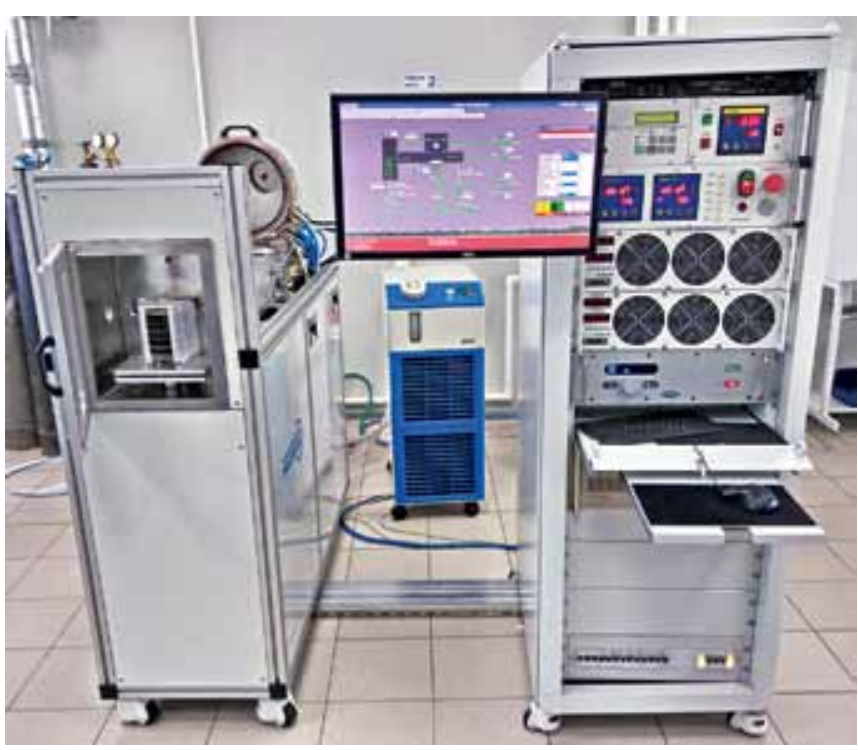

Pис.1. Внешний вид установки "МАГНА ТМ 150-01К" Fig.1. Appearance of "MАГНА ТМ 150-01K" installation

на всех стадиях технологического процесса нанесения [2].

\section{ОПИСАНИЕ И ПРИНЦИП РАБОТЫ}

На рис.1 представлен внешний вид установки, в состав которой входят шлюзовая камера с кассетой, транспортная камера с манипулятором, технологический модуль, а также стойка питания и управления.

Установка работает следующим образом. Загрузка и выгрузка кассеты 12 с пластинами происходит вручную через шлюзовую камеру 1 (рис.2). После создания требуемого предельного давления с помощью средств вакуумной откачки 7, 9 и 11 открывается затвор 2, и манипулятор 10 поштучно транспортирует пластины из кассеты на подложкодержатель 8 , который нагревает подложку 6 до $300^{\circ} \mathrm{C}$. Газовый канал с отдельным регулятором подачи аргона под пластину обеспечивает равномерный прогрев ее поверхности. После этого пластина подвергается ионной очистке в плазме ВЧ газового разряда за счет подачи ВЧ-потенциала на подложкодержатель.

Таблица 1. Режимы ВЧ-очистки

Table 7. HF cleaning modes

\begin{tabular}{|l|c|}
\hline Поток аргона, л/ч & 1,4 \\
\hline Рабочее давление, Па & 1,8 \\
\hline Мощность, Вт & 100 \\
\hline Время, мин & 10 \\
\hline
\end{tabular}

Для генерации наносимого материала применяется мультикатодное магнетронное распылительное устройство с тремя планарными мишенями 3 и 4 диаметром 100 мм и толщиной 6 мм (третья мишень на схеме не показана). Заслонка 5 поворачивается и последовательно открывает мишени при выполнении техпроцесса. Подложкодержатель обеспечивает плавное вращение пластин вокруг вертикальной оси с частотой до 20 об/мин. По окон ${ }^{-}$ чании процесса манипулятор возвращает обработанную пластину в ее ячейку в кассете и берет следующую необработанную пластину.

\section{МЕТОДИКА ЭКСПЕРИМЕНТА И РЕЗУЛЬТАТЫ}

На установке "МАГНА ТМ 150-01K" проводилось нанесение многослойной металлизации на кремниевые пластины диаметром 100 мм. В одном цикле вакуумирования в режиме со-распыления последовательно наносились слои титана (Ti), нитрида титана (TiN) и алюминия (Al). Такие многослойные функциональные структуры применяются при создании тонкопленочных схем в СВЧ-приборах.

Подобранные режимы очистки пластин с использованием ВЧ-генератора мощностью 600 Вт представлены в табл.1. Эффективность данной операции

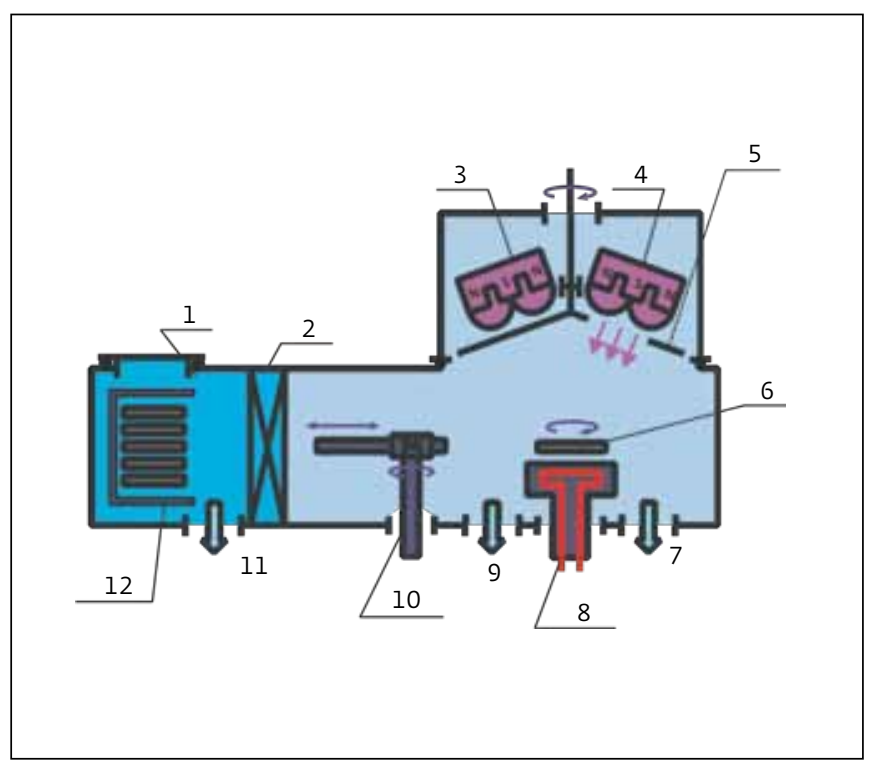

Pис.2. Принципиальная схема установки "МАГНА ТМ 150-01K": 1 - шиюзовая камера; 2-затвор; 3, 4-мишень; 5 -заслонка 6 - подложка; 7, 9, 11 - средства вакуумной откачки; 8 - подложкодержатель; 10 - манипулятор; 12 - кассета с пиастинами

Fig.2. Principal diagram of "МАГНА ТМ 150-01K": 1 - lock chamber; 2 - lock; 3, 4 - target; 5 - shutter; 6 - substrate; 7, 9, 11 - vacuum pumping capabilities; 8 - substrates supporter; 10 - manipulator; 12 -cassette with plates 
Таблица 2. Оценка эффективности ВЧ-очистки

Table 2. Effectiveness of HF cleaning

\begin{tabular}{|c|c|c|c|c|}
\hline Номер точки & $\mathrm{SiO}_{2}$ до травления, нм & SiO $_{2}$ после травления, нм & Изменение толщины ( $\Delta$ ), нм & $\Delta_{c p}, H M$ \\
\hline 1 & 318 & 300,93 & 17,07 & \multirow{5}{*}{15,11} \\
\hline 2 & 325,98 & 313,14 & 12,84 & \\
\hline 3 & 316,79 & 302,93 & 13,86 & \\
\hline 4 & 316,53 & 302,24 & 14,29 & \\
\hline 5 & 320,25 & 302,76 & 17,49 & \\
\hline
\end{tabular}

Таблица 3. Oптимальные режимы нанесения покрытий

Table 3. Optimal modes of coating deposition

\begin{tabular}{|c|c|c|c|c|c|}
\hline Покрытие & $\begin{array}{c}\text { Поток } \\
\text { аргона, л/ч }\end{array}$ & $\begin{array}{c}\text { Поток } \\
\text { азота, л/ч }\end{array}$ & $\begin{array}{c}\text { Рабочее } \\
\text { давление, Па }\end{array}$ & $\begin{array}{c}\text { Мощность одной } \\
\text { мишени, Вт }\end{array}$ & Температура, ${ }^{\circ} \mathrm{C}$ \\
\hline $\mathrm{Ti}$ & 1,00 & - & 0,45 & 1500 & 200 \\
\hline TiN & 0,40 & 0,34 & 0,33 & 1500 & 200 \\
\hline Al & 1,10 & - & 0,52 & 1500 & 150 \\
\hline
\end{tabular}

оценивалась путем измерения толщины слоя диоксида кремния $\left(\mathrm{SiO}_{2}\right)$ до очистки и после нее. Толщина контролировалась по пяти точкам на различных участках пластины (рис.3), таким образом, была получена информация о неравномерности травления материала. Средняя скорость очистки составила

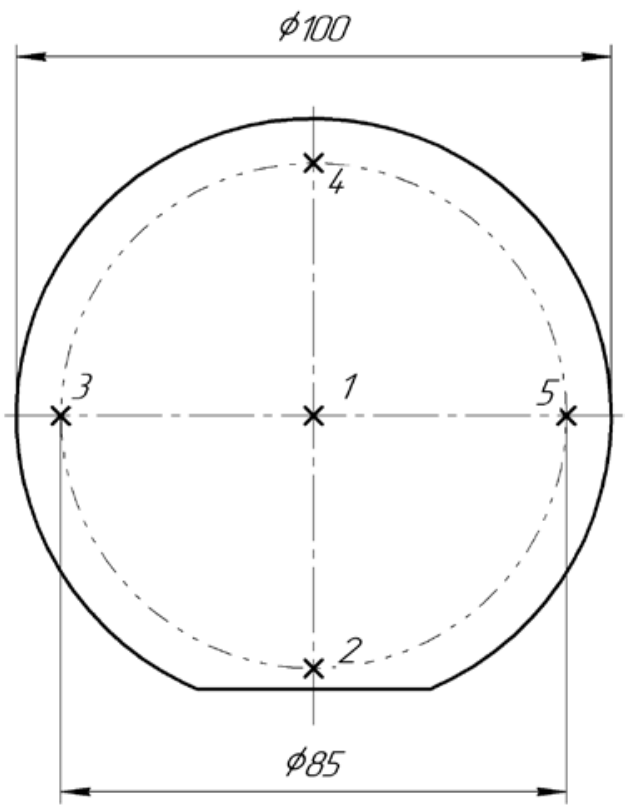

Рис.3. Расположение контрольных точек на пластине Fig.3. The location of control points on the plate
1,511 нм/мин. Результаты измерений представлены в табл.2.

Оптимальные режимы нанесения слоев Тi, TiN и Al (табл.3) выбирались исходя из следующих критериев: максимальная производительность, стабильность магнетронного разряда, состав и структура покрытия. При этом покрытия Ti и TiN формировались с использованием одной титановой мишени, а для нанесения Al применялись две одновременно работающие алюминиевые мишени. В эксперименте использовались два источники питания постоянного тока мощностью 3 кВт. Переключение первого источника питания между титановой мишенью и одной из алюминиевых мишеней происходило с использованием устройства коммутации. Второй источник питания всегда был подключен ко второй алюминиевой мишени.

Известно, что наилучшими характеристиками (по критерию удельного электрического сопротивления) обладает соединение титана с азотом в соотношении атомов $1: 1\left(\mathrm{Ti}_{1} \mathrm{~N}_{1}\right)$ [3]. На начальной стадии для первичной оценки структуры покрытия контролировался его цвет: стехиометрический нитрид титана имеет золотистый блеск, фиолетовый оттенок указывает на избыток азота, серый - на его недостаток. Окончательная оптимизация режимов формирования требуемой структуры проводилась на основе данных анализа элементного состава. Результат исследования покрытия, полученного после заключительной корректировки параметров нанесения, показал 


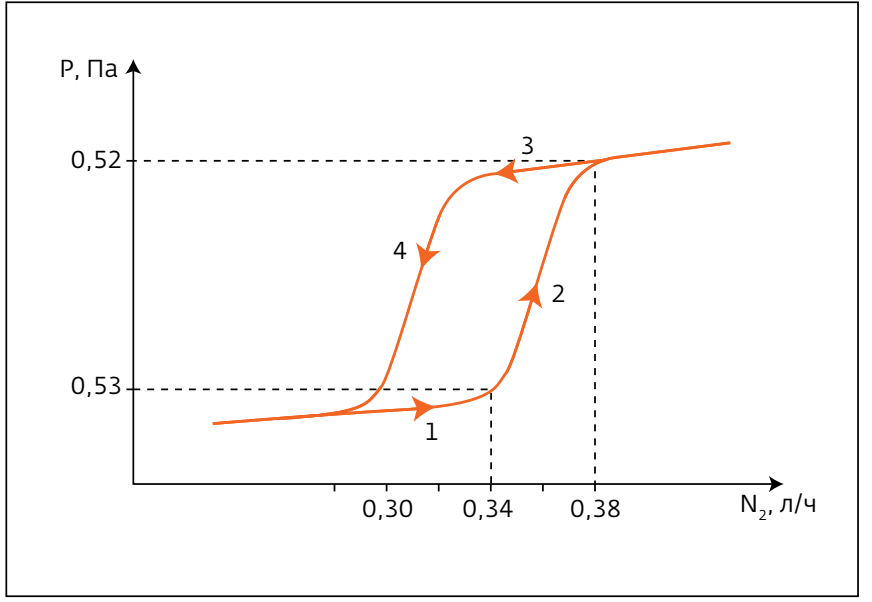

Puc.4. Гистерезис рабочего давления при нанесении TiN Fig.4. Working pressure hysteresis when deposition of TiN

количественное содержание азота на уровне $53,65 \%$, а удельное электрическое сопротивление пленки составило 216 мкОм·см.

Характер восстановления давления в рабочей камере установки "МАГНА ТМ 150-01К" в зависимости от потока азота в процессе нанесения нитрида титана иллюстрирует график, представленный на рис.4. На участке 1-2 при увеличении концентрации азота в плазме начинается процесс активного азотирования титановой мишени, вследствие чего содержание Ті в рабочем объеме резко сокращается, а так как титан является геттером, то и давление растет скачкообразно. При уменьшении расхода азота (участок 3-4) скорость азотирования постепенно уменьшается и становится равной скорости распыления нитрида и, как только TiN полностью удален с поверхности мишени, давление в камере становится прежним из-за начала распыления чистого титана.

\section{РЕЗУЛЬТАТЫ И ОБСУЖДЕНИЕ}

О производительности установки "МАГНА ТМ 15001K" при металлизации пластин указанными металлами можно судить по скорости их осаждения. Результаты измерений толщины покрытий каждого материала представлены в табл.4. Таким образом, средняя скорость нанесения Ті и $\mathrm{TiN}$ с использованием одного магнетрона равна 70 и 60 нм/мин соответственно; скорость нанесения Al с одновременным применением двух магнетронов - 254 нм/мин.

\section{Выводы}

Установка "МАГНА ТМ 150-01K" позволяет проводить нанесение многослойных функциональных
Таблища 4. Толщины покрытий

Table 4. Thickness of coatings

\begin{tabular}{|c|c|c|}
\hline Покрытие & Время нанесения, мин & Толщина, нм \\
\hline $\mathrm{Ti}$ & 1 & 70 \\
\hline $\mathrm{TiN}$ & 2 & 120 \\
\hline $\mathrm{Al}$ & 5 & 1270 \\
\hline
\end{tabular}

тонкопленочных покрытий магнетронным распылением в одном технологическом цикле. При этом формируются качественные многослойные тонкие пленки, обладающие хорошей прочностью сцепления между основой и адгезионным слоем, а также между отдельными слоями. Автоматическая система управления установки контролирует все параметры процесса и поддерживает их стабильность согласно заданным значениям, обеспечивая хорошую воспроизводимость свойств наносимых покрытий. Размещение оборудования данного типа в чистых производственных помещениях позволит значительно снизить привносимую дефектность пластин, что способствует повышению выхода годных изделий.

\section{ЛИТЕРATУPA / REFERENCE}

1. Одиноков В.В., Павлов Г.Я., Панин В.В., Путырский В.В., Ращинский В.П., Шпаков А.Н., Шубников А.В. Малогабаритная вакуумная установка "МВУ ТМ - Магна 3M" для нанесения многослойных металлических покрытий методом магнетронного распыления // Наноинженерия. 2014. № 9. С. 8-11.

2. Каракулов Р.А., Одиноков В.В., Панин В.В., Шубников А.В., Владимиров Д.С., Владимиров С.В., Голубцов А.А. Установка магнетронного распыления "Магна ТМ 7" в технологии создания тонкопленочных ГИС СВЧ // Наноиндустрия. 2017. № 2. С. 80-86.

3. Grigoriev S.N., Melnik Yu.A., Metel A.S., Panin V.V. Cutting Tools Nitriding in Plasma Produced by a Fast Neutral Molecule Beam // Japan. J. Appl. Phys. 2011. V50. 08JG04.

4. Метель А.С., Мельник Ю.А., Краснов П.С., Нэй Х.А. Улучшение адгезии осаждаемого магнетронным методом покрытия при подаче на подложку импульсов высокого напряжения // Вестник МГТУ "СТАНКИН". 2016. № 4. С. 36-39.

5. Метель А.С., Григорьев С.Н., Волосова М.А., Мельник Ю.А. Магнетронное распылительное устройство с генерацией импульсных пучков высокоэнергетических атомов газа // Приборы и техника эксперимента. 2017. № 2. С. 144-151. 